\title{
Commentary on the medium-term results of ceramic-on-polyethylene Zweymüller-Plus total hip arthroplasty
}

CH Yan *, FRCSEd(Orth), FHKAM (Orthopaedic Surgery)

Department of Orthopaedics and Traumatology, The University of Hong Kong, Queen Mary Hospital, Pokfulam, Hong Kong

*Corresponding author: yanchoi@hku.hk

Hong Kong Med J 2017;23:417-8

DOI: 10.12809/hkmj175070

In their retrospective review, $\mathrm{Li}$ et $\mathrm{al}^{1}$ have described the medium-term clinical and radiological results of Zweymüller-Plus total hip arthroplasty (THA) in 185 Chinese patients (207 hips). The articulation size was $28 \mathrm{~mm}$, with conventional ultra-highmolecular-weight polyethylene (UHMWPE) over the acetabular side and third-generation alumina ceramics on the femoral side. Due to the number of patients lost to follow-up and other reasons, the final numbers of patients and hips available for analysis were 156 and 175, respectively. The mean duration of follow-up was 14.1 years. The series comprised both primary and revision THA cases. One should be aware of the complexity of the latter and that their results may not be directly comparable with the former. All the surgeries were performed before the year 2000, when UHMWPE was still widely used around the world.

The authors reported satisfactory clinical outcomes. ${ }^{1}$ Two out of 175 hips were revised, making the true revision rate of $1.1 \%$, excluding those who were lost to follow-up. Two hips were found to have excessive polyethylene wear, although the authors did not define 'excessive'. Osteolysis or radiolucent lines were detected in $4 \%$ of the femora and $1.7 \%$ of the acetabula. There are three major limitations in this study in terms of measuring polyethylene wear and survival analysis. First, the method used to measure UHMWPE liner wear in the study was imprecise, as admitted by the authors. The modern standard of measuring wear requires the use of computer software based on the concentricity of the hip ball and liner. ${ }^{2}$ Second, the authors mentioned that their desired acetabular component position was $45^{\circ} \pm 10^{\circ}$ of abduction and $15^{\circ} \pm 10^{\circ}$ of anteversion. However, they did not reveal the mean postoperative angles, although malpositioning of the acetabular component is a known risk factor of excessive polyethylene wear. Third, the high number of patients lost to follow-up (13.5\%) might have underestimated the revision rate and overestimated the overall survival of the prostheses.

Chiu et $\mathrm{al}^{3}$ reported the results of THA in patients below 40 years of age and found UHMWPE wear and osteolysis in $56 \%$ of the hips with $28-\mathrm{mm}$ metal on UHMWPE articulation. Of note, UHMWPE has inferior wear resistance and therefore generates wear particles that induce osteolysis and cause aseptic loosening in THA.-8 Highly cross-linked polyethylene (HXLPE) was introduced for clinical use in THA in 1998, aiming to reduce wear and improve its longevity. ${ }^{9}$ In-vitro ${ }^{9-13}$ and in-vivo ${ }^{11,14-17}$ studies suggested that HXLPE had superior wear resistance and caused less osteolysis. Li et $\mathrm{al}^{18}$ studied the linear penetration of HXLPE in young Chinese patients with THA and found the wear rate was $0.025 \mathrm{~mm} /$ year.

In their meta-analysis, Kurtz et $\mathrm{al}^{19}$ also investigated the incidence of osteolysis in patients with UHMWPE liners and HXLPE liners by calculating odds ratios from individual cohort $(n=8)$ and randomised controlled trial $(n=1)$ studies with a minimum of 5-year follow-up. The combined and the pooled odds ratio was estimated to be 0.131 (95\% confidence interval [CI], 0.064-0.268) using a random-effects model which indicates that the incidence of osteolysis was $87 \%$ lower in patients with HXLPE liners compared with patients with conventional polyethylene liners. ${ }^{19}$ Hanna et $\mathrm{al}^{20}$ followed a cohort of 160 patients (179 THAs) between the ages of 45 and 65 years who received liners made of either UHMWPE $(n=89)$ or HXLPE $(n=88)$. The cumulative implant survival, with revision for polyethylene wear or osteolysis as an endpoint, was $86 \%$ (95\% CI, 78\%-94\%) in the UHMWPE group and $100 \%$ in the HXLPE group at 13 years postoperatively. ${ }^{20}$ Data from a United States registry also suggested that the revision rates for THAs utilising HXLPE are lower than that for noncrosslinked UHMWPE. Paxton et $\mathrm{al}^{21}$ found that at 7 years of follow-up, the cumulative incidence of revision was $5.4 \%$ (95\% CI, 4.4\%-6.7\%) for metal-onUHMWPE compared with 2.8\% (95\% CI, 2.6\%-3.2\%) for metal-on-HXLPE.

In their study, $\mathrm{Li}$ et $\mathrm{al}^{1}$ did not explain in detail why their cohort showed a much lower incidence of excessive polyethylene wear or aseptic loosening compared with the literature. One possible explanation could be the age of the studied patients: more than half of their patients were older than 60 
years. It is well known that 'wear is a function of use, not time.' Elderly patients are generally less physically active, and this results in less wear.

The study by $\mathrm{Li}$ et $\mathrm{al}^{1}$ demonstrated good clinical and radiological outcomes with THA with ceramic on UHMWPE articulation in a Chinese population. The data, however, are of little clinical significance in today's practice as most of the THAs utilised HXLPE liner; UHMWPE liners are obsolete.

\section{References}

1. Li H, Zhang S, Wang XM, Lin JH, Kou BL. Medium-term results of ceramic-on-polyethylene Zweymüller-Plus total hip arthroplasty. Hong Kong Med J 2017;23:333-9.

2. Devane PA, Bourne RB, Rorabeck CH, Hardie RM, Horne JG. Measurement of polyethylene wear in metal-backed acetabular cups. I. Three-dimensional technique. Clin Orthop Relat Res 1995;319:303-16.

3. Chiu KY, Tang WM, Ng TP, Poon KC, Ho WY, Lee KM Cementless total hip arthroplasty in young Chinese patients: a comparison of 2 different prostheses. J Arthroplasty 2001;16:863-70.

4. Harris WH. The problem is osteolysis. Clin Orthop Relat Res 1995;(311):46-53.

5. Harris WH. Wear and periprosthetic osteolysis: the problem. Clin Orthop Relat Res 2001;(393):66-70.

6. Maloney WJ, Galante JO, Anderson M, et al. Fixation, polyethylene wear, and pelvic osteolysis in primary total hip replacement. Clin Orthop Relat Res 1999;(369):157 64.

7. Oparaugo PC, Clarke IC, Malchau H, Herberts P. Correlation of wear debris-induced osteolysis and revision with volumetric wear-rates of polyethylene: a survey of 8 reports in the literature. Acta Orthop Scand 2001;72:22-8.

8. Sochart DH. Relationship of acetabular wear to osteolysis and loosening in total hip arthroplasty. Clin Orthop Relat Res 1999;(363):135-50.

9. Ries MD, Scott ML, Jani S. Relationship between gravimetric wear and particle generation in hip simulators: conventional compared with cross-linked polyethylene. J Bone Joint Surg Am 2001;83-A Suppl 2 Pt 2:116-22.

10. Kurtz SM, Austin MS, Azzam K, et al. Mechanica properties, oxidation, and clinical performance of retrieved highly cross-linked Crossfire liners after intermediateterm implantation. J Arthroplasty 2010;25:614-23.e1-2.

11. Muratoglu OK, Greenbaum ES, Bragdon CR, Jasty M, Freiberg AA, Harris WH. Surface analysis of early retrieved acetabular polyethylene liners: a comparison of conventional and highly crosslinked polyethylenes. J Arthroplasty 2004;19:68-77.

12. Muratoglu OK, Merrill EW, Bragdon CR, et al. Effect of radiation, heat, and aging on in vitro wear resistance of polyethylene. Clin Orthop Relat Res 2003;(417):253-62.

13. Saikko V, Calonius O, Keränen J. Wear of conventional and cross-linked ultra-high-molecular-weight polyethylene acetabular cups against polished and roughened $\mathrm{CoCr}$ femoral heads in a biaxial hip simulator. J Biomed Mater Res 2002;63:848-53.

14. Digas G, Kärrholm J, Thanner J, Malchau H, Herberts P. The Otto Aufranc Award. Highly cross-linked polyethylene in total hip arthroplasty: randomized evaluation of penetration rate in cemented and uncemented sockets using radiostereometric analysis. Clin Orthop Relat Res 2004;(429):6-16.

15. Glyn-Jones S, Isaac S, Hauptfleisch J, McLardy-Smith P, Murray DW, Gill HS. Does highly cross-linked polyethylene wear less than conventional polyethylene in total hip arthroplasty? A double-blind, randomized, and controlled trial using roentgen stereophotogrammetric analysis. J Arthroplasty 2008;23:337-43.

16. Heisel C, Silva M, dela Rosa MA, Schmalzried TP. Shortterm in vivo wear of cross-linked polyethylene. J Bone Joint Surg Am 2004;86-A:748-51.

17. Martell JM, Verner JJ, Incavo SJ. Clinical performance of a highly cross-linked polyethylene at two years in total hip arthroplasty: a randomized prospective trial. J Arthroplasty 2003;18(7 Suppl 1):55-9.

18. Li D, Yan CH, Ng FY, Chiu KY. Highly crosslinked polyethylene wear in primary total hip arthroplasty in young Chinese patients-a 6-year follow-up. Chin J Arthroplasty 2011;5-5:593-600.

19. Kurtz SM, Gawel HA, Patel JD. History and systematic review of wear and osteolysis outcomes for first-generation highly crosslinked polyethylene. Clin Orthop Relat Res 2011;469:2262-77.

20. Hanna SA, Somerville L, McCalden RW, Naudie DD, MacDonald SJ. Highly cross-linked polyethylene decreases the rate of revision of total hip arthroplasty compared with conventional polyethylene at 13 years' follow-up. Bone Joint J 2016;98-B:28-32.

21. Paxton EW, Inacio MC, Namba RS, Love R, Kurtz SM. Metal-on-conventional polyethylene total hip arthroplasty bearing surfaces have a higher risk of revision than metalon-highly crosslinked polyethylene: results from a US registry. Clin Orthop Relat Res 2015;473:1011-21. 